Article

\title{
Mottainai!-A Practice Theoretical Analysis of Japanese Consumers' Food Waste Reduction
}

\author{
Noora Sirola, Ulla-Maija Sutinen *, Elina Närvänen $『$, Nina Mesiranta and Malla Mattila \\ Faculty of Management and Business, Tampere University, FI-33014 Tampere, Finland; \\ noora.sirola@gmail.com (N.S.); elina.narvanen@tuni.fi (E.N.); nina.mesiranta@tuni.fi (N.M.); \\ malla.mattila@tuni.fi (M.M.) \\ * Correspondence: ulla-maija.sutinen@tuni.fi
}

Received: 31 October 2019; Accepted: 21 November 2019; Published: 25 November 2019

check for updates

\begin{abstract}
This study focuses on food waste and its reduction by describing and analyzing the food waste-related everyday life of Japanese consumers through a practice theoretical lens. The research enables paying attention to the role of culture in sustainable consumer behavior, which is a largely unexplored area in previous food waste research. The methodological approach is qualitative and the empirical data of the study were generated through mobile ethnography. It combines elements from diary methods, multi-sited ethnography, and digital ethnography, producing visual and textual data of the practices that the participants of the study considered meaningful. The analysis identifies materials, meanings, and competences of the practices related to food waste reduction. These practices were interlinked with five broader food-related practices: planning, grocery shopping, cooking, eating, and handling surplus food. The findings reveal specific elements related to Japanese culture such as mottainai-a concept used to express the regret of wasting something valuable. The study contributes to the literature on sustainable consumption by emphasizing the importance of identifying and understanding how culturally linked practices may support sustainable (or unsustainable) consumption.
\end{abstract}

Keywords: food waste; consumers; culture; japan; households; practices

\section{Introduction}

Food waste, simply defined as edible food lost from food production and consumption [1], is an increasing sustainability issue. Unused and/or unconsumed food affects the worldwide pricing of food and causes water shortages, having negative effects on both society and individual consumers [2]. As Aschemann-Witzel et al. [3] (p. 6458) argue, "food itself and the resources exploited in its production, transportation or disposal are used inefficiently" when food is not used for eating [3]. Food waste is also linked to social injustice: the amount of global food waste would be enough to feed all the people suffering from undernourishment [4]. Previous research has shown that households are the biggest contributors of food waste emergence in developed countries (e.g., [5,6]). Food waste studies at the household level have largely focused on reasons for food waste emergence. It has been demonstrated that the emergence of food waste is related to consumer attitudes (e.g., [7]), awareness (e.g., [8]), and everyday practices such as food acquisition, preparation, and provisioning [9-11]. However, it is also important to study active food waste reduction in everyday life as part of sustainable consumption [12], in order to better capture the consumer practices that support food waste reduction.

Although previous studies have provided insights into food waste-related behavior in everyday life, these studies have so far had little to say about the role of culture in it. Food and eating are strongly connected to culture: they embed cultural meanings, symbols, signs, customs, and routines [13]. For example, the definition of edibility varies in different cultures [14], which is also connected to 
the perceptions of what constitutes food waste [15]. In addition, many food waste studies have been conducted in Western cultural contexts, thus neglecting other cultures such as Asia (for a few exceptions, see e.g., $[16,17])$. Therefore, approaching food waste and its reduction empirically from a cultural perspective provides a novel understanding about the issue [6].

Japan as a cultural context offers an interesting avenue for this type of research. In Japan, almost half of food waste comes from households: yearly as much as 2,8 million tons of food [18], thus following similar findings from European countries. More interestingly, however, the Japanese consumption culture features dimensions that can be seen as directly related to causing food waste, such as high quality expectations and aesthetics of food [19]. Even though Japan is a significant economy in financial terms, only a few studies in the field of consumer behavior have focused on Japanese consumers [20].

The purpose of the study is to better understand how Japanese consumers reduce their food waste in their everyday life. In order to meet the purpose, we adopt a practice theoretical lens to describe and analyze the food waste-related everyday lives of Japanese consumers. The research questions are as follows: (1) What are the key elements of Japanese consumers' food waste reduction practices? and (2) How do these practices appear as part of their food-related everyday life? Conducting a mobile ethnographic study, we identified materials, meanings, and competences [21] related to reducing food waste in the everyday lives of 13 Japanese study participants. Our research is in line with earlier literature suggesting that understanding consumer-citizens, who can be regarded as forerunners of sustainability changes, requires an approach that embraces the social, cultural and institutional aspects steering consumers' everyday life [22]. This study offers an original contribution to studies on food waste reduction by emphasizing a cultural understanding of consumers' everyday life. This complements and broadens the theoretical view of how consumers reduce their food waste: not only as a conscious cognitive pursuit, but as a cultural practice. The findings contribute to the literature on sustainable consumption by highlighting the role of culture and practices in sustainable consumer behavior.

\section{Theoretical Framework}

\subsection{Consumer Food Waste Reduction}

Although the majority of food waste research has put its emphasis on the emergence of food waste and reasons for it, there are also studies that have focused on consumer food waste reduction and related behavior. These studies have varied in their theoretical perspectives on consumer behavior and utilized different kinds of methodologies, both quantitative and qualitative.

The major stream of food waste reduction research has viewed the topic from psychological or cognitive perspective, focusing on themes such as attitudes, awareness, motivation, and intentions. Attitudes have been in the interest of several researchers aiming at understanding the consumer behavior related to food waste reduction (see e.g., [8,23,24]). When it comes to awareness, Schmidt's [25] study based on environmental psychology has proposed that both appropriate knowledge (awareness) and goal-setting support consumer's food waste reduction behavior. On the other hand, it has also been found that consumers are already rather well-aware of the consequences of food waste but still continue wasting food [23]. Researchers have also studied how to predict consumers' intentions to reduce household food waste [26].

According to an alternative view, focusing solely on a psychological approach to consumer behavior and aspects taking place inside a consumer's mind is too short sighted when it comes to food waste reduction. From this perspective, researchers have put their focus on social, cultural, and material aspects of food waste reduction (e.g., [12,27-29]). Previous research on food waste reduction has brought up the importance of dining practices; such as practicing thrift during mealtimes [27], and sharing food in a social setting [30]. In addition to dining practices, Mattila et al. [29] have introduced several time-related bundles of practices embedded in consumers' everyday life that are connected to the 
reduction of food waste. Furthermore, Evans [28] has focused on the flow of food surplus and identified surplus handling practices, such as gifting and recovery, which in part reduce the amount of binned surplus food.

In terms of cultural differences, consumer food waste-related behavior, attitudes, and perceptions have been studied in different countries. Secondi, Principato and Laureti [31] utilized Eurobarometer survey data on the EU-27 countries and found territorial differences between European countries in household food waste behavior. Examples of country-specific studies on consumer food waste in the EU include those conducted in the UK [32,33], Italy [8,34], Germany [35], Greece [24], Romania [36,37], Denmark [38], and Finland [39]. Additionally Asian countries such as China [40], Japan [17], and Lebanon [41], as well as Arab countries [42] have received attention. In the Americas, US [43,44], Canadian [7] as well as Brazilian [45] consumers have been examined. Even though studies on consumer food waste have been conducted in various countries, the cultural aspects of behavior as they appear in consumers' everyday lives have not been elaborated in detail. In the following section, we introduce the cultural perspective on food waste-related practices.

\subsection{Cultural Perspective on Food Waste-Related Practices}

Culture constantly modifies the ways we (un)consciously behave. Culture is often seen as a system of shared values, norms, and meanings (e.g., [46]). However, according to Swidler [47], these dimensions are not sufficient in explaining the role of culture as they may represent mere intentions rather than behavior. Thus, culture should be seen as an enabler for action by 'shaping a repertoire or "tool kit" of habits, skills, and styles from which people construct "strategies of action"' [48] (p. 273).

Other researchers have also acknowledged the role of individual action in building and shaping culture. According to McCracken [23], culture, on the one hand, is to be seen as a lens through which an individual views various phenomena and, on the other hand, the trace of human behavior. Moisander and Valtonen [49] urge to approach culture as produced in the everyday lives of individuals; consumers are to be seen as active individuals who interpret culturally affected meanings based on context(s). However, cultural theories are often criticized for their focus on meanings, thus forgetting the importance of the materiality of consumption [50]. A practice theoretical approach adopted in this study enables overcoming this criticism.

The practice theoretical approach shifts the attention from individuals, their intentions, and attitudes to actual behavior [51]. The social world is seen to be constructed of various practices that exist only when people perform them [51-53]. Practices are linked to one another and can be defined as routine-like behavior, which consists of several interconnected elements: bodily and mental activities, things and the use of them as well as background knowledge such as understanding, know-how, emotions, and motivations [51]. Paying attention to consumers' everyday practices, which may include some resource-consuming activities, can be regarded as being a fruitful approach to understand sustainable consumption [22]. Focusing on the interconnections between these practices can shed light on important aspects regarding behavior change toward sustainability [54].

Recently, the practice theoretical approach has gained popularity among researchers in the field of sustainable consumption $[10,55]$. Consumers use material resources such as raw materials, water, and electricity while performing their daily practices, so studying these practices can offer new possibilities to change them to become more sustainable [49]. As suggested by Mylan et al. [56], consumption in the home is a complex phenomenon, and questions of how instead of what of how much should be asked more often when addressing everyday consumption and its sustainability. Earlier research has suggested that sustainable food practices can either be part of wider food practices (e.g., part of planned food practices) or distinct practices themselves [57].

In this study, we follow Shove, Pantzar, and Watson [21], who have argued that practices consist of materials, meanings, and competences. Materials consist of various objects, spaces, infrastructure, tools, and technology that are required to perform practices [21], Here, the materials are understood as 
ingredients, tools and equipment (e.g., kitchen appliances), and spaces (e.g., kitchen, supermarket, and workplace) that are related to food and food waste-related everyday life. In theories of practice, the body can be seen as both a material element [21] and a carrier and performer of practices [52]. In this study, humans are approached as material objects who simultaneously connect various materials, meanings, and competences in a single practice, and further to other practices.

Meanings refer to social and symbolic meanings of participating in practices [21]. They represent how people make sense of the surrounding world: what we consider desirable and what kind of feelings are related to action [53]. Meanings are bound to social contexts. Therefore, for example, some symbols, purposes, and goals may be understood only within certain groups. Here, meanings refer to consumers' thoughts, attitudes, and feelings related to food waste. For example, those can mean guilt, joy of succeeding as a cook and not wasting food, or attitudes towards leftovers [11,33].

Competences refer to the skills, knowledge, and capabilities needed to perform practices [52]. According to Shove, Pantzar, and Watson [21], they are practical understandings that give individuals the ability to act. Competences combine previous understanding [51] and enable practices. In the food waste context, competences may be related to cooking and using leftovers, understanding date labels, and other skills having a role in food waste-related practices $[11,58]$.

\section{Methodology}

To make sense of the consumers' food waste related practices, this study adopts qualitative research methodology and approaches food (waste) consumption from the perspective of interpretive consumer research, which views reality as socially constructed, multiple, holistic, and contextual [59]. As a data generation tool, this study utilizes mobile ethnography, which is a combination of diary methods [60,61], multi-sited ethnography [62], and digital ethnography [63,64]. Unlike traditional ethnography, which has required researchers to participate personally in the lives or communities that they research, mobile ethnography utilizes the fact that people today carry their smartphones constantly with them wherever they go [64] (p. 267). Hence, data can be generated on the spot without the researcher's physical presence in the situation, also in more private settings such as the consumer's home. The identified strengths of the method also include accessibility, immediacy and audiovisual presence [64] (p. 267). The adopted approach enables generating data that consist of aspects that the participants of the study consider relevant.

Drawing from diary methods, our approach makes it possible to record, observe, and understand thoughts and perceptions as they are experienced $[60,61]$. As consumers' everyday lives take place in multiple connected places and can be difficult to reach and observe, we chose to utilize multi-sited ethnographic observation [62], and digital and mobile technologies such as cameras and mobile phones to generate the data (e.g., [65]). Mobile ethnography with diary-like photos and text was seen as a fruitful way to elaborate on the participants' daily practices while still acknowledging food waste as a sensitive topic.

The data for the study were generated with a mobile application EthOS, which is a tool made for ethnographic research [66]. In EthOS, a researcher can give the study participants various tasks in the form of text, photos, videos, and audio. In this study, 13 Japanese participants were given a total of 16 food waste-related tasks in Japanese in January-February 2018. At the beginning of the research project, the participants replied to questions about their household size, their demographic features, their profession, and their relationship with food and food waste in general. Then, they received instructions for downloading the application onto their smartphone. During the project, they received tasks to complete. By responding to the tasks, they sent the materials through their phones to the researcher. The data were instantly collected in the application task by task to be analyzed and interpreted further. The first author of this article regularly reminded participants to complete the tasks. The tasks are detailed in Table 1 (translated into English from Japanese). 
Table 1. Tasks given to the study participants.

\begin{tabular}{|c|c|}
\hline Task & Task Description \\
\hline Orientation task 1 & $\begin{array}{l}\text { Introduce your kitchen-What kind of cooking appliances and kitchen devices do } \\
\text { you have? Do you use them to reduce food waste? }\end{array}$ \\
\hline Orientation task 2 & Did food end up in the trash today? (Respond on several days) \\
\hline Orientation task 3 & If food ended up in the trash, what was the reason? (Respond on several days) \\
\hline Orientation task 4 & $\begin{array}{l}\text { Free discussion: What kind of thoughts and feelings you have regarding food waste? } \\
\text { Please tell freely about your thoughts and habits related to food waste. }\end{array}$ \\
\hline Tasks 5-7 (Week 1) & $\begin{array}{l}\text { Take a picture or video clip of your daily food shopping. (Task 5) } \\
\text { How is food waste visible in your lunch or dinner (at work, at home or at school)? } \\
\text { (Task 6) } \\
\text { Investigate the food items you have at home. Are there some items in which the } \\
\text { expiry date has passed? If yes, do you still intend to use them, or throw away? } \\
\text { How will you act? Why has it happened? (Task 7) }\end{array}$ \\
\hline Tasks 8-11 (Week 2) & $\begin{array}{l}\text { What kind of leftovers do you have from yesterday or the weekend? What are you } \\
\text { planning to do to them? (Task 8) } \\
\text { Try to cook food using leftovers from previous days or the scraps of food items. } \\
\text { Make a video clip where you show what and how you cooked it. (Task 9) } \\
\text { What do you consider the influence of Japanese culture or your being a Japanese } \\
\text { person in your food related everyday life (e.g., food purchasing, shopping, } \\
\text { storing food, eating out, valuing food, and thoughts related to food)? (Task 10) } \\
\text { Do you use certain kitchen appliances or devices to reduce or prevent food waste or } \\
\text { to minimize its amount? (Task 11) }\end{array}$ \\
\hline Tasks 12-16 (Week 3) & $\begin{array}{l}\text { Share something related to food waste in your everyday life. E.g., how do you reduce } \\
\text { food waste or how do you generally act to reduce it? (Task 12) } \\
\text { Share some special event related to food waste that you run into in your daily life. } \\
\text { It can also be an earlier event, or you can also imagine what it could be. (Task 13) } \\
\text { How do you plan your food-related everyday life? Do you plan what you are going } \\
\text { to cook, or do you make shopping lists? (Task 14) } \\
\text { Try to organize your fridge or pantry so that you could avoid food waste. Send a } \\
\text { picture or video clip before and after the organizing. (Task 15) } \\
\text { How do you feel your current family situation and lifestyle is affecting your food } \\
\text { related everyday life and food waste? (Task 16) }\end{array}$ \\
\hline
\end{tabular}

The first author of the paper conducted the mobile ethnography in practice, as she is familiar with the Japanese culture and proficient in the language. The participants were purposefully selected by utilizing the social networks of the researchers, on the basis of their interest to participate in a food-waste related study, and to represent varying professions and life situations. The final data of the study consisted of 114 text and photo entries and were complemented with emails from the participants (see Figure 1). 


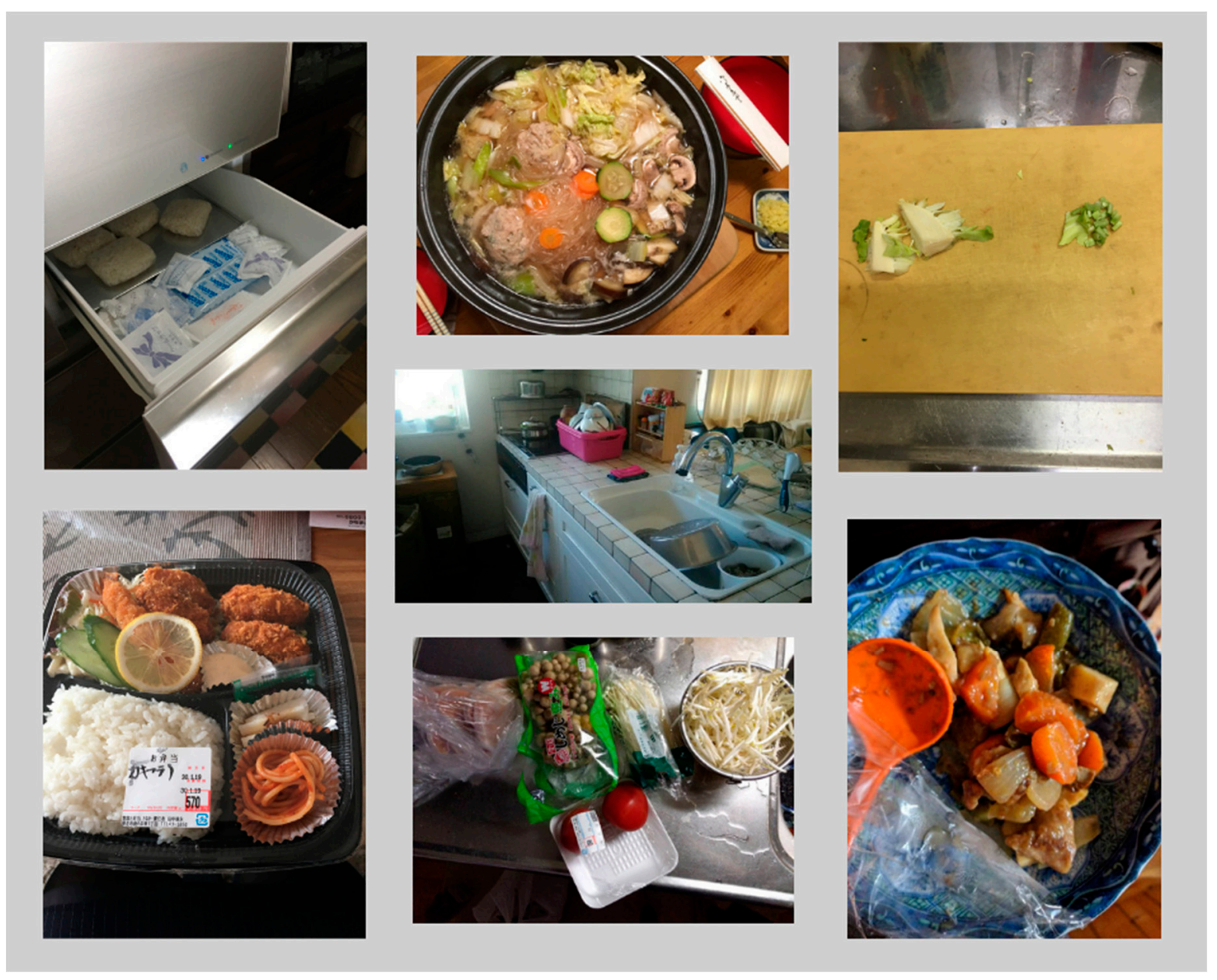

Figure 1. Collage of example photo entries posted to EthOS.

The analysis process was highly iterative, switching between data generation and analysis [67]. The initial tasks were planned using the theoretical background of practice theory, the researcher's pre-understanding of Japanese culture and previous studies of food waste behaviors as an inspiration. During the research, some tasks were fine-tuned as the researchers' understanding of the phenomenon evolved and developed. For instance, it was noticed that there was very little waste emerging and much effort was put onto reducing and preventing waste. The tasks were re-directed to focus more directly on these practices. The data was analyzed mostly in the Ethos application which offers a way to tag and categorize postings in the web-based interface of the program. The data were coded with keywords first inductively and then by connecting the themes with practice theoretical elements. After this, conceptual maps were built to explore connections between different codes. After many rounds of categorization and abstraction [67], the data were classified into the three elements of practice [21]. Subsequently, a more inductive coding phase resulted in identifying five food-related practices connecting the previously identified food waste reduction elements. The findings of the study with representative citations are presented and discussed next.

\section{Findings: Food Waste Reducing Practices}

The data indicated that the participants had various food waste reduction practices that were interlinked with five broader food-related practices: planning, grocery shopping, cooking, eating, and handling surplus food. Within these practices different materials, meanings, and competences were emphasized, further highlighting the dynamic nature of everyday practices and their connection to the Japanese culture. Table 2 summarizes the findings, next elaborated in more detail. 
Table 2. The identified practices and the elements within them.

\begin{tabular}{llll}
\hline $\begin{array}{l}\text { Food-Related } \\
\text { Practice }\end{array}$ & Materials & Meanings & Competences \\
\hline Planning & $\begin{array}{l}\text { Shopping list } \\
\text { Ingredients at home } \\
\text { Food to be prepared }\end{array}$ & $\begin{array}{l}\text { Necessity } \\
\text { Desire to consume everything }\end{array}$ & $\begin{array}{l}\text { Anticipating consumption } \\
\text { Anticipating when the food } \\
\text { will go bad }\end{array}$ \\
\hline $\begin{array}{l}\text { Grocery } \\
\text { shopping }\end{array}$ & $\begin{array}{l}\text { Package size } \\
\text { Food to be prepared }\end{array}$ & $\begin{array}{l}\text { Necessity } \\
\text { Mottainai }\end{array}$ & $\begin{array}{l}\text { Anticipating consumption } \\
\text { Rules of thumb }\end{array}$ \\
\hline \multirow{2}{*}{$\begin{array}{l}\text { Rooking } \\
\text { Eating }\end{array}$} & $\begin{array}{l}\text { Frozen and ready-made food } \\
\text { Date labels }\end{array}$ & $\begin{array}{l}\text { Precision, appreciation of food } \\
\text { Desire to consume everything } \\
\text { Mottainai }\end{array}$ & $\begin{array}{l}\text { Evaluating the edibility of } \\
\text { food, self-confidence } \\
\text { Using ingredients fully } \\
\text { Anticipating consumption }\end{array}$ \\
\hline \multirow{3}{*}{$\begin{array}{l}\text { Fandling } \\
\text { surplus food }\end{array}$} & $\begin{array}{l}\text { Previously prepared food } \\
\text { Leftovers } \\
\text { New meals }\end{array}$ & $\begin{array}{l}\text { Mottainai } \\
\text {-Precision, appreciation of the } \\
\text { food }\end{array}$ & $\begin{array}{l}\text { Anticipating when the food } \\
\text { will go bad } \\
\text { Evaluating the edibility of } \\
\text { food, self-confidence }\end{array}$ \\
\hline
\end{tabular}

\subsection{Planning}

The first identified food waste reduction practices were related to planning, which has been identified as an important practice in previous research as well [11,33]. The participants had a habit of writing a shopping list and checking the pantry or fridge before going grocery shopping in order to buy the necessary and planned ingredients: 'I look at the fridge and write a list before going shopping. Sometimes I first decide what I will prepare and after that write the ingredients into the list' (Haruto, 30).

Planning did not only occur before shopping and cooking but was performed constantly within everyday life. Reducing food waste required continuously paying attention to the appropriate amount of food. This indicates how constant planning and the ability to anticipate food consumption as well as the lifespan of food products help to reduce food waste.

The data indicated that the constant planning aimed at consuming all the food. When planning the next meal, the participants considered dishes that could be prepared using the already existing ingredients. When buying groceries and cooking the meals, the participants kept in mind when the food will be needed and how many people are eating it. If there were leftovers, it was common to try to eat the food in the order they were anticipated to go bad. Therefore, the desire not to waste a single ingredient constantly guided the participants' food waste behavior.

\subsection{Grocery Shopping}

During grocery shopping, the participants had a habit of buying only the planned ingredients that were needed for the next cooking and consumed certainly in the near future. Many participants were used to going often to the store, even daily. They rarely stocked food in advance, which helped consuming everything in time. Additionally, Williams et al. [58] found that those who do grocery shopping often produce less food waste.

The participants had so-called rules of thumb, for example only buying food for the next three days, going to the supermarket every three days, or spending no more than a certain sum of money per month on food. These principles helped them buy the right amount of food and only those ingredients that were needed soon. They also helped cooking the right amount of food so that everything could be eaten at once: 'I only buy food for the next 3 days or a maximum of one week. I only cook the amount that is needed for people eating on that day' (Rio, 22). 
Small, single-unit package sizes that are common in Japan [44] made it easy to buy the amount that could be consumed at once while enabling to cook versatile meals and not-too-big an amount at a time: 'In Japan, all food products are sold in small portions. As a foreigner, it may feel far too little but in Japanese cuisine, it is common to use a little bit of everything in cooking, so I think the amount is just fine.' (Yui, 23)

Some participants thought that due to the small package sizes, no extra ingredients that would easily end up getting spoilt remained after cooking. In earlier research, too large package sizes have been identified as a source of food waste in households [68]. Even though small single-unit packages may not be optimal in terms of packaging materials, they may, on the other hand, make it easier to consume ingredients fully and help reduce food waste.

An exception to this practice was ready-to-eat food products or products that required only a little preparation such as adding boiled water. According to the participants, the frozen and ready-to-eat food products in Japan are highly developed with a great variety. Food could be stocked without the fear of it getting spoilt even though one was living alone. As these food products required only a little preparation, they made the everyday cooking easier while still making it possible to eat well. Therefore, as pointed out also by Southerton and Yates [10], one way to reduce food waste could be to favor dishes with a simple preparation process.

\subsection{Cooking}

When cooking, many participants carefully used all the edible parts of the ingredients as efficiently as possible. The precision in using ingredients fully was also demonstrated in the photos of the participants' daily food waste, mostly containing only inedible parts of vegetables and used tealeaves. Our data thus indicate that the concept of food waste is understood differently in different cultures (e.g., [69]). This was also supported by the participants' knowledge of the ways to use vegetable peels and fish all the way to skin and bones. The participants appeared to be creative and conscious of various ways of using ingredients, also those maybe not that common in Western cultures.

As rice can be said to be the basis of Japanese food culture, it is no surprise that it was also linked to the participants' food waste. However, the data brought up practices that helped preventing rice waste. Rice was usually cooked daily and consumed fully during the same day. The participants used their freezers to store rice for longer periods or even cooked it only to freeze it in ready-to-eat portions. Having cooked rice ready to be eaten made everyday life easier while simultaneously stretching the lifespan of rice and ensuring it stayed fresh (e.g., [12]).

Not trusting date labels blindly was also important in reducing food waste. The participants were used to consuming food products despite their expired dates as they felt able to assess the edibility using their senses. Especially products with long shelf life, such as spices and canned food, were often used regardless of the expired dates if they still looked, tasted, and smelled normal: 'Here is umeboshi [pickled plums]. Even though the best before date has expired, it would be such a waste to throw it away so I will still eat it. I will throw it away if it starts smelling bad.' (Nana, 21)

The citation above also brings up the idea of wastefulness, which was central in many participants' posts. In Japanese culture, there is a specific term to describe the wastefulness of something valuable such as food and money, mottainai. It can be translated as 'What a waste' and is used to express the regret of throwing something valuable away. The idea of mottainai emphasizes the appreciation toward food and the understanding of its finiteness. The idea of mottainai seemed to guide the participants' behavior in various everyday situations and facilitated precision in consuming ingredients fully. The following quotation illustrates this: 'The expression and idea of mottainai is infiltrated to Japanese people and I, as well, keep that always in mind' (Miyu, 49). Not only was mottainai visible in cooking-related posts but it also guided the participants to buy only necessary food products, consume all the leftovers, and plan so that nothing goes to waste. Further, when asking the participants about their overall thoughts about food waste, some of them answered concisely: 'Mottainai'. 


\subsection{Eating}

According to Southerton and Yates [10], meal occasions are strongly related to the emergence of food waste. In this study, practices related to eating were not as central as the other food-related practices. Not taking too much food and eating the food in order so that nothing gets spoilt were, however, identified in our data too. Family was seen helpful as more food was consumed daily compared to living alone. Single participants reported that they sometimes had trouble with excess food. The data indicated that through planned shopping and cooking, food waste could be minimized also during eating. The participants aimed at cooking food so that everything could be eaten during one day or meal, which resulted in no waste or leftovers either during meal occasions: 'In my family we have a habit of buying and cooking main and side dishes the amount that can be eaten fully in one or two meals so food waste is unlikely.' (Nana, 21).

\subsection{Handling Surplus Food}

In handling surplus food, creativity and knowledge of the multiple ways of using food products appeared crucial. In addition to rice, vegetables were seen as tricky when reducing food waste as they were seen to spoil quickly. The participants had a habit of making soups or smoothies from the wilted fruit and vegetables: 'I do buy vegetables a bigger amount at a time but if they seem to get spoilt, I make a soup out of them.' (Misaki, 27).

The Japanese culture played a role in the dishes prepared from leftover food. While Western consumers stretch the lifespan of leftovers by using them in casseroles or pies [70], one of the participants told how she tends to use extra kara age, Japanese deep-fried chicken, to prepare oyakodon, a Japanese chicken and egg bowl.

Even though Japanese are known for their appreciation for aesthetics and demand for high quality [70], our participants were not that strict with the flawlessness of the food at home. Perhaps guided by the idea of mottainai, the participants used all edible parts of wilted vegetables and consumed expired products if they appeared safe to eat. The participants' posts demonstrated that wasting food was considered wrong and the efficient use of ingredients was desirable, even an issue to be proud of. Most of the participants considered leftovers and surplus foods as similar to other foods and were used to eating them. Some participants froze leftovers or ingredients such as extra meat so that they would not get spoilt and could be used when needed. Some of the participants discussed how the tasks had made them pay more attention to their food waste. Many were also happy about how little food waste they actually produced.

\section{Discussion}

Adopting a cultural perspective and a solution orientation to consumer food waste reduction, this study provides novel insights to consumers' food waste behavior. In earlier literature, food waste has been connected to not only cooking and eating, but also preparing and provisioning [10]. With this study, this perspective was further extended, resulting in proposing that reducing food waste is related to several everyday practices, from planning to handling surplus food, all of which entail different elements.

Based on our findings, we argue that some of the meanings guiding consumers' food waste behavior, such as mottainai, are deeply rooted in the cultural context. Considering food waste reduction as a part of sustainable consumption, these cultural meanings are important to identify and understand. When aiming at finding solutions to unsustainable consumption, adopting a cultural perspective offers valuable contributions for understanding consumers' behavior. In this study, the cultural meanings supported food waste reduction, but in some cases these kinds of meanings might contribute to unsustainable behavior and emergence of food waste. For instance, the Porpino et al. [45] have identified the social norm of parent as a 'good provider' and able to offer options for the children resulting in the emergence of household food waste. 
As mentioned in the section focusing on the theoretical background, earlier food waste reduction research have been conducted in various countries, thus in various cultural contexts. The country contexts of these studies have often been located in the Western part of the world. Thus, researching food waste practices in the Japanese context provides a novel viewpoint to household food waste reduction research. The majority of this research has focused on Western cultures and therefore mirrors specific issues related to these countries. However, the highly developed, dense-populated areas in Asia play a crucial role in the global food waste issue [1]. To grasp the impact of culture on food waste-related behavior, more research should be conducted in different cultural contexts (e.g., [42]).

While conducting the study, firstly, we noticed that the participants had specific viewpoints on what food waste is [42]. Food waste included, for instance, fish bones, which are not usually considered edible at any point and therefore not considered food waste [1]. This implies that existing definitions of food waste are socio-culturally bounded constructs. This notion has a resemblance to the approach of Audet and Brisebois [71] who argue that food waste can be viewed as socially produced through various interactions and practices among actors. Instead of aiming for an exhaustive concept definition, we suggest that further research should pay more attention to connections between food waste definitions and culture.

Our findings uncovered many different practices supporting participants' food waste reduction and prevention. This is very likely due to the methodology of our study, mobile ethnography, which in part encouraged and inspired the participants to reduce food waste. Although in this case the digital application was used as a methodological tool, the potential of digital appliances and applications has been introduced in food waste reduction research. Several studies have focused on the effect of digital applications on the amount of food waste created. The possible supporting role of mobile applications [72,73] as well as other technological appliances [74] has been examined. It has also been argued that consumers are willing to receive more information about the novel technologies utilized in the food industry, such as food irradiation, that may, in part, result in food waste reduction $[75,76]$.

\section{Conclusions}

The objective of the study was to describe and analyze the food waste-related everyday life of Japanese consumers through a practice theoretical lens. Visual and textual data were collected utilizing mobile ethnography. The analysis identified five interlinked food-related practices: planning, grocery shopping, cooking, eating, and handling surplus food. Furthermore, we analyzed the meanings, materials, and competences of food waste reduction related to each practice. The findings identified new aspects in food waste reduction practices that were strongly connected to Japanese culture. Hence, they offer a novel, cultural perspective to food waste-related practices. The theoretical implications of this perspective emphasize the importance of analyzing food waste reduction within the context of consumers' everyday life, which is always embedded in culture.

The managerial implications of the study are related to the utilizing the cultural insights in order to develop packaging and product innovations that help consumers reduce food waste. For instance, smaller package sizes were perceived to facilitate the purchase and use of appropriate amount of food. Food manufacturers could also include information and practical tips in their packaging and marketing communications, such as how to use the whole product. Furthermore, retailers can influence consumers' everyday practices through their own mobile applications. The ways of how this can be implemented should be tailored according to the cultural context. Additionally, introducing effective ways of reducing food waste from one cultural context to another is a fruitful opportunity in the global consumer culture, where ideas and consumption practices can easily spread through, for instance, social media. Political actors should also adopt this cultural orientation into their interventions and campaigns directed at consumers rather than focusing only on awareness building. The effectiveness of different interventions and campaigns depend on the cultural context. 
Author Contributions: Conceptualization, all authors; Methodology, all authors; Data Generation, N.S.; Initial Data Analysis, N.S. and E.N.; Writing - Original Draft Preparation, N.S. and U.S., Writing - Review and Editing, all authors.

Funding: This research was funded by Emil Aaltonen foundation, Finland.

Acknowledgments: We thank the study participants, and anonymous reviewers for their effort in this research.

Conflicts of Interest: The authors declare no conflict of interest.

\section{References}

1. Lipinski, B.; Hanson, C.; Waite, R.; Searchinger, T.; Lomax, J.; Kitinoja, L. Reducing Food Loss and Waste; Working Paper, Installment 2 of Creating a Sustainable Food Future; World Resources Institute: Washington, DC, USA, 2013; Available online: http://www.wri.org/publication/reducing-food-loss-and-waste/ (accessed on 1 June 2019).

2. Graham-Rowe, E.; Jessop, D.C.; Sparks, P. Identifying motivations and barriers to minimising household food waste. Resour. Conserv. Recycl. 2014, 84, 15-23. [CrossRef]

3. Aschemann-Witzel, J.; De Hooge, I.; Amani, P.; Bech-Larsen, T.; Oostindjer, M. Consumer-related food waste: Causes and potential for action. Sustainability 2015, 7, 6457-6477. [CrossRef]

4. Melikoglu, M.; Lin, C.; Webb, C. Analysing global food waste problem: Pinpointing the facts and estimating the energy content. Open Eng. 2013, 3, 157-164. [CrossRef]

5. Bräutigam, K.R.; Jörissen, J.; Priefer, C. The extent of food waste generation across EU-27: Different calculation methods and the reliability of their results. Waste Manag. Res. 2014, 32, 683-694. [CrossRef]

6. Porpino, G. Household food waste behavior: Avenues for future research. J. Assoc. Consum. Res. 2016, 1, 41-51. [CrossRef]

7. Parizeau, K.; von Massow, M.; Martin, R. Household-level dynamics of food waste production and related beliefs, attitudes, and behaviours in Guelph, Ontario. Waste Manag. 2015, 35, 207-217. [CrossRef] [PubMed]

8. Principato, L.; Secondi, L.; Pratesi, C.A. Reducing food waste: An investigation on the behavior of Italian youths. Br. Food J. 2015, 117, 731-748. [CrossRef]

9. Evans, D. Beyond the throwaway society: Ordinary domestic practice and a sociological approach to household food waste. Sociology 2012, 46, 41-56. [CrossRef]

10. Southerton, D.; Yates, L. Exploring food waste. In Waste Management and Sustainable Consumption: Reflections on Consumer Waste; Ekström, K.M., Ed.; Routledge: Abingdon, UK, 2015; pp. 133-149.

11. Närvänen, E.; Mesiranta, N.; Hukkanen, A. The quest for an empty fridge. In The Practice of the Meal: Food, Families and the Market Place; Cappellini, B., Marshall, D., Parsons, E., Eds.; Routledge: Abingdon, UK, 2016; pp. 208-219.

12. Närvänen, E.; Mesiranta, N.; Sutinen, U.-M.; Mattila, M. Creativity, aesthetics and ethics of food waste in social media campaigns. J. Clean. Prod. 2018, 195, 102-110. [CrossRef]

13. Rozin, P. The meaning of food in our lives: A cross-cultural perspective on eating and well-being. J. Nutr. Educ. Behav. 2005, 37, 107-112. [CrossRef]

14. Asp, E.H. Factors affecting food decisions made by individual consumers. Food Policy 1999, 24, $287-294$. [CrossRef]

15. Blichfeldt, B.S.; Mikkelsen, M.; Gram, M. When it stops being food: The edibility, ideology, procrastination, objectification and internalization of household food waste. Food Cult. Soc. 2015, 18, 89-105. [CrossRef]

16. Grandhi, B.; Appaiah Singh, J. What a waste! A study of food wastage behavior in Singapore. J. Food Prod. Market. 2016, 22, 471-485. [CrossRef]

17. Liu, C.; Hotta, Y.; Santo, A.; Hengesbaugh, M.; Watabe, A.; Totoki, Y.; Allen, D.; Bengtsson, M. Food waste in Japan: Trends, current practices and key challenges. J. Clean. Prod. 2016, 133, 557-564. [CrossRef]

18. FAO. Mottainai! What a Waste! Japan Staves Off the Worst of 'Food Waste Culture'. Available online: http://www.fao.org/save-food/news-and-multimedia/news/newsdetails/en/c/1036297/ (accessed on 8 June 2019).

19. Kim, R. Japanese consumers' use of extrinsic and intrinsic cues to mitigate risky food choices. Int. J. Consum. Stud. 2008, 32, 49-58. [CrossRef]

20. Schiele, K.; Venkatesh, A. Regaining control through reclamation: How consumption subcultures preserve meaning and group identity after commodification. Consump. Mark. Cult. 2016, 19, 427-450. [CrossRef] 
21. Shove, E.; Pantzar, M.; Watson, M. The Dynamics of Social Practice: Everyday Life and How It Changes; Sage: London, UK, 2012.

22. Mylan, J. Sustainable consumption in everyday life: A qualitative study of UK consumer experiences of meat reduction. Sustainability 2018, 10, 2307. [CrossRef]

23. Fiore, M.; Pellegrini, G.; Sala, P.L.; Conte, A.; Liu, B. Attitude toward food waste reduction: The case of Italian consumers. Int. J. Glob. Small Bus. 2017, 9, 185-201. [CrossRef]

24. Abeliotis, K.; Lasaridi, K.; Chroni, C. Attitudes and behaviour of Greek households regarding food waste prevention. Waste Manag. Res. 2014, 32, 237-240. [CrossRef]

25. Schmidt, K. Explaining and promoting household food waste-prevention by an environmental psychological based intervention study. Resour. Conserv. Recycl. 2016, 111, 53-66. [CrossRef]

26. Graham-Rowe, E.; Jessop, D.C.; Sparks, P. Predicting household food waste reduction using an extended theory of planned behaviour. Resour. Conserv. Recycl. 2015, 101, 194-202. [CrossRef]

27. Cappellini, B.; Parsons, E. Practising thrift at dinnertime: Mealtime leftovers, sacrifice and family membership. Sociol. Rev. 2012, 60, 121-134. [CrossRef]

28. Evans, D. Binning, gifting and recovery: The conduits of disposal in household food consumption. Environ. Plan. D 2012, 30, 1123-1137. [CrossRef]

29. Mattila, M.; Mesiranta, N.; Närvänen, E.; Koskinen, O.; Sutinen, U.-M. Dances with potential food waste: Organising temporality in food waste reduction practices. Time Soc. 2019, 28, 1619-1644. [CrossRef]

30. Lazell, J. Consumer food waste behaviour in universities: Sharing as a means of prevention. J. Consum. Beh. 2016, 15, 430-439. [CrossRef]

31. Secondi, L.; Principato, L.; Laureti, T. Household food waste behaviour in EU-27 countries: A multilevel analysis. Food Policy 2015, 56, 25-40. [CrossRef]

32. Mallinson, L.J.; Russell, J.M.; Barker, M.E. Attitudes and behaviour towards convenience food and food waste in the United Kingdom. Appetite 2016, 103, 17-28. [CrossRef]

33. Quested, T.E.; Marsh, E.; Stunell, D.; Parry, A.D. Spaghetti soup: The complex world of food waste behaviours. Resour. Conserv. Recycl. 2013, 79, 43-51. [CrossRef]

34. Fanelli, R. Using causal maps to analyse the major root causes of household food waste: Results of a survey among people from Central and Southern Italy. Sustainability 2019, 11, 1183. [CrossRef]

35. Richter, B. Knowledge and perception of food waste among German consumers. J. Clean. Prod. 2017, 166, 641-648. [CrossRef]

36. Ghinea, C.; Ghiuta, O.A. Household food waste generation: Young consumers behaviour, habits and attitudes. Int. J. Environ. Sci. Technol. 2019, 16, 2185-2200. [CrossRef]

37. Stefan, V.; van Herpen, E.; Tudoran, A.A.; Lähteenmäki, L. Avoiding food waste by Romanian consumers: The importance of planning and shopping routines. Food Qual. Prefer. 2013, 28, 375-381. [CrossRef]

38. Aschemann-Witzel, J.; de Hooge, I.E.; Almli, V.L.; Oostindjer, M. Fine-tuning the fight against food waste. J. Macromark. 2018, 38, 168-184. [CrossRef]

39. Silvennoinen, K.; Katajajuuri, J.M.; Hartikainen, H.; Heikkilä, L.; Reinikainen, A. Food waste volume and composition in Finnish households. Br. Food J. 2014, 116, 1058-1068. [CrossRef]

40. Zhang, H.; Duan, H.; Andric, J.M.; Song, M.; Yang, B. Characterization of household food waste and strategies for its reduction: A Shenzhen City case study. Waste Manag. 2018, 78, 426-433. [CrossRef]

41. Mattar, L.; Abiad, M.G.; Chalak, A.; Diab, M.; Hassan, H. Attitudes and behaviors shaping household food waste generation: Lessons from Lebanon. J. Clean. Prod. 2018, 198, 1219-1223. [CrossRef]

42. Abiad, M.G.; Meho, L.I. Food loss and food waste research in the Arab world: A systematic review. Food Secur. 2018, 10, 311-322. [CrossRef]

43. Neff, R.A.; Spiker, M.; Rice, C.; Schklair, A.; Greenberg, S.; Leib, E.B. Misunderstood food date labels and reported food discards: A survey of US consumer attitudes and behaviors. Waste Manag. 2019, 86, 123-132. [CrossRef]

44. Qi, D.; Roe, B.E. Household food waste: Multivariate regression and principal components analyses of awareness and attitudes among U.S. consumers. PLoS ONE 2016, 11, 1-19. [CrossRef]

45. Porpino, G.; Parente, J.; Wansink, B. Food waste paradox: Antecedents of food disposal in low income households. Int. J. Consum. Stud. 2015, 39, 619-629. [CrossRef]

46. Hofstede, G. Culture and organizations. Int. Stud. Manag. Organ. 1980, 10, 15-41. [CrossRef]

47. Swidler, A. Culture in action: Symbols and strategies. Am. Sociol. Rev. 1986, 51, 273-286. [CrossRef] 
48. McCracken, G. Culture and consumption: A theoretical account of the structure and movement of the cultural meaning of consumer goods. J. Consum. Res. 1986, 13, 71-84. [CrossRef]

49. Moisander, J.; Valtonen, A. Qualitative Marketing Research: A Cultural Approach; Sage: London, UK, 2006.

50. Warde, A. After taste: Culture, consumption and theories of practice. J. Consum. Cult. 2014, 14, $279-303$. [CrossRef]

51. Reckwitz, A. Toward a theory of social practices: A development in culturalist theorizing. Eur. J. Soc. Behav. 2002, 32, 195-217. [CrossRef]

52. Warde, A. Consumption and theories of practice. J. Consum. Cult. 2005, 5, 131-153. [CrossRef]

53. Røpke, I. Theories of practice-New inspiration for ecological economic studies on consumption. Ecol. Econ. 2009, 68, 2490-2497. [CrossRef]

54. Paddock, J. Household consumption and environmental change: Rethinking the policy problem through narratives of food practice. J. Consum. Cult. 2017, 17, 122-139. [CrossRef]

55. Welch, D.; Warde, A. Theories of practice and sustainable consumption. In Handbook of Research on Sustainable Consumption; Reisch, L., Thøgersen, J., Eds.; Edward Elgar Publishing: Cheltenham, UK, 2015; pp. 84-100.

56. Mylan, J.; Holmes, H.; Paddock, J. Re-introducing consumption to the 'circular economy': A sociotechnical analysis of domestic food provisioning. Sustainability 2016, 8, 794. [CrossRef]

57. Halkier, B. A practice theoretical perspective on everyday dealings with environmental challenges of food consumption. Anthropol. Food 2009, 5. [CrossRef]

58. Williams, H.; Wikström, F.; Otterbring, T.; Löfgren, M.; Gustafsson, A. Reasons for household food waste with special attention to packaging. J. Clean. Prod. 2012, 24, 141-148. [CrossRef]

59. Tadajewski, M. Remembering motivation research: Toward an alternative genealogy of interpretive consumer research. Mark. Theory 2006, 6, 429-466. [CrossRef]

60. Bolger, N.; Davis, A.; Rafaeli, E. Diary methods: Capturing life as it is lived. Annu. Rev. Psychol. 2003, 54, 579-616. [CrossRef] [PubMed]

61. Patterson, A. Processes, relationships, settings, products and consumers: The case for qualitative diary research. Qual. Mark. Res. Int. J. 2005, 8, 142-156. [CrossRef]

62. Marcus, G.E. Ethnography in/of the world system: The emergence of multi-sited ethnography. Annu. Rev. Anthropol. 1995, 24, 95-117. [CrossRef]

63. Murthy, D. Digital ethnography: An examination of the use of new technologies for social research. Sociology 2008, 42, 837-855. [CrossRef]

64. Kozinets, R.V. Netnography: The Essential Guide to Qualitative Social Media Research, 3rd ed.; Sage: London, UK, 2020.

65. Spinney, J. A chance to catch breath: Using a mobile video ethnography in cycling research. Mobilities 2011, 6, 161-182. [CrossRef]

66. EthOS. Available online: https://ethosapp.com (accessed on 30 August 2019).

67. Spiggle, S. Analysis and interpretation of qualitative data in consumer research. J. Consum. Res. 1994, 21, 491-503. [CrossRef]

68. Kojima, R.; Ishikawa, M. Consumer willingness-to-pay for packaging and contents in Asian countries. Waste Manag. 2017, 68, 724-731. [CrossRef]

69. Parry, A.; Bleazard, P.; Okawa, K. Preventing FoodWaste: Case Studies of Japan and the United Kingdom. OECD Food, Agriculture and Fisheries Papers. 2015. Available online: https://www.oecd-ilibrary.org/ agriculture-and-food/preventing-food-waste_5js4w29cf0f7-en (accessed on 7 August 2019).

70. Synodinos, N.E. Understanding Japanese consumers: Some important underlying factors. Jpn. Psychol. Res. 2001, 43, 235-248. [CrossRef]

71. Audet, R.; Brisebois, É. The Social Production of Food Waste at the Retail-Consumption Interface. Sustainability 2019, 11, 3834. [CrossRef]

72. Farr-Wharton, G.; Choi, J.H.J.; Foth, M. Food talks back: Exploring the role of mobile applications in reducing domestic food wastage. In Proceedings of the 26th Australian Computer-Human Interaction Conference on Designing Futures: The Future of Design, Association for Computing Machinery (ACM), Sydney, Australia, 5-7 December 2014; pp. 352-361.

73. Mattila, M.; Mesiranta, N.; Heikkinen, A. Platform-based sustainable business models: Reducing food waste in food services. Int. J. Entrep. Innov. Manag. 2019, in press. 
74. Hebrok, M.; Boks, C. Household food waste: Drivers and potential intervention points for design-An extensive review. J. Clean. Prod. 2017, 151, 380-392. [CrossRef]

75. Galati, A.; Moavero, P.; Crescimanno, M. Consumer awareness and acceptance of irradiated foods: The case of Italian consumers. Br. Food J. 2019, 121, 1389-1412. [CrossRef]

76. Galati, A.; Tulone, A.; Moavero, P.; Crescimanno, M. Consumer interest in information regarding novel food technologies in Italy: The case of irradiated foods. Food Res. Int. 2019, 119, 291-296. [CrossRef]

(C) 2019 by the authors. Licensee MDPI, Basel, Switzerland. This article is an open access article distributed under the terms and conditions of the Creative Commons Attribution (CC BY) license (http://creativecommons.org/licenses/by/4.0/). 